\title{
Blepharophimosis and its association with female infertility
}

\author{
C. A. JONES AND J. R. O. COLlin
}

From Moorfields Eye Hospital, City Road, London EC1V 2PD.

SUMMARY This study confirms the previously suggested high incidence of menstrual irregularity and infertility in females with the blepharophimosis syndrome.

Blepharophimosis was first described by Dimitry ${ }^{1}$ in 1921. The cases in that family were reviewed by Owens et al. ${ }^{2}$ in 1960. Many authors have documented the primary features of this syndrome, namely, blepharophimosis, blepharoptosis, epicanthus inversus, and telecanthus (Fig. 1). Kohn and Romano $^{3}$ stressed the importance of telecanthus and noted a number of associated features including esotropia, inferior oblique overaction, coloboma of the optic disc, and low set cupped ears. A number of other features have been described, including hypoplasia of the levator muscle and tarsal plate, ${ }^{4} \mathrm{~S}$-shaped upper lid margins, and lower lid lateral ectropion. ${ }^{2}$ Garden ${ }^{5}$ noted abnormalities of the lacrimal system, punctal reduplication, and stenosis of the canaliculi, and McIllroy ${ }^{6}$ commented on the occurrence of divergent strabismus and nystagmus.

A number of authors have commented on the transmission of the blepharophimosis syndrome by dominant inheritance, noting that it was passed on mainly by affected males. ${ }^{27-9}$ Townes and Muechler ${ }^{10}$ described a family with blepharophimosis, and their proband, a 29-year-old girl, had primary amenorrhea. It is possible that preferential male transmission occurs because of reduced fertility in females with blepharophimosis. This study was undertaken to evaluate this hypothesis.

\section{Subjects and methods}

We reviewed the blepharophimosis patients and their families who have been seen in the Ophthalmic Plastic Clinics in Moorfields Hospital and the Hospital for Sick Children, Great Ormond Street, London. The fertility and menstrual pattern of females of child bearing age were investigated. Thirty-seven patients out of 54 known cases of blepharophimosis were Correspondence to Mr J. R. O. Collin, FRCS. reviewed; 20 were female and 17 male. A positive family history was obtained in 17 of the 37 patients, male transmission occurring on 18 occasions and female transmission on eight. Six females in our series were of child bearing age, their ages ranging from 17 to 33 years. Estimation of gonadotrophins-luteinising hormone (LH) and follicle stimulating hormone (FSH)-oestrogen and progesterone, and testosterone were performed on each woman.

\section{Results}

Two of the six women had normal menstrual periods, three had scanty irregular periods with no definite cycle, and one had primary amenorrhoea. One of the women with normal periods had a single offspring and one woman with irregular periods had suffered 3 miscarriages. Evaluation of the hormone results was difficult because the majority of the women had irregular cycles. In five of the six cases an abnormal pattern of results was obtained (Table 1), but only

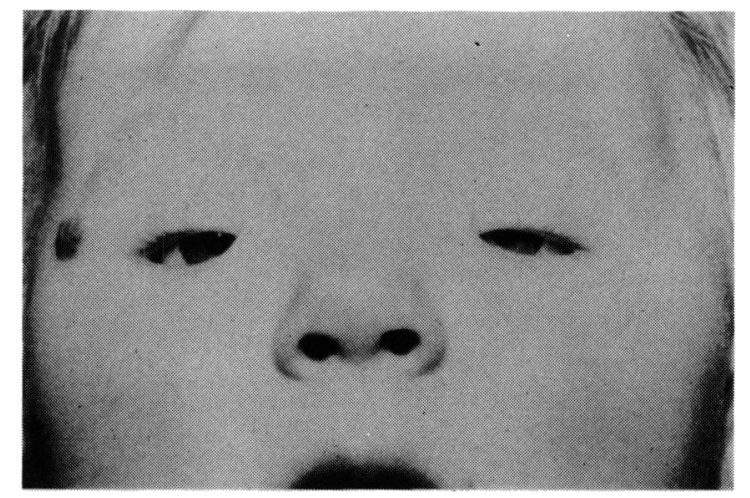

Fig. 1 Patient with the blepharophimosis syndröme. 
Table 1 Hormonal blood levels in women of childbearing age

\begin{tabular}{|c|c|c|c|c|c|c|}
\hline Cases & 1 & 2 & 3 & 4 & 5 & 6 \\
\hline LH U/I & $7 \cdot 4$ & $7 \cdot 3$ & $274 \uparrow$ & $29 \cdot 6 \uparrow$ & $28 \cdot 8 \uparrow$ & $15 \cdot 1 \uparrow$ \\
\hline FSH U/l & $2 \cdot 2$ & $4 \cdot 1$ & $22 \cdot 1 \uparrow$ & $11 \cdot 1 \uparrow$ & $14.6 \uparrow$ & $>25 \uparrow$ \\
\hline Oestrogen $\mathrm{pmol} / \mathrm{l}$ & $1600 \uparrow$ & 350 & 270 & $1050 \uparrow$ & 260 & $<50 \downarrow$ \\
\hline Progesterone $\mathrm{nmol} / \mathrm{l}$ & $5 \cdot 1$ & $5 \cdot 8$ & $3 \cdot 8$ & $10 \cdot 5$ & $12 \cdot 4$ & $6 \cdot 3$ \\
\hline Testosterone $\mathrm{nmol} / \mathrm{l}$ & - & $14 \cdot 1$ & $2 \cdot 2$ & - & $2 \cdot 0$ & $2 \cdot 0$ \\
\hline Menstruation & Absent & Normal & Irregular & $\begin{array}{l}\text { Absent for } \\
6 \text { months }\end{array}$ & Irregular & Normal \\
\hline
\end{tabular}

one of these patients was definitely hypogonadal, with raised gonadotrophins and low oestrogen and progesterone. In the remaining four patients the precise cause of abnormal menstruation was not ascertained, and it was not feasible to pursue further more invasive investigations in this study.

\section{Discussion}

The previous literature on blepharophimosis has concentrated on the associated abnormalities of extraocular structures. Although several authors have commented on the differential transmission of the blepharophimosis syndrome, only one paper reports the association of blepharophimosis and amenorrhea. Our study highlights the high incidence of menstrual irregularities and infertility among women with blepharophimosis, two-thirds of our group of child bearing age having abnormal periods. The cause of menstrual irregularity was not necessarily the result of hypogonadism, as has been previously suggested. A surprisingly high proportion of our patients with blepharophimosis, $50 \%$ of cases, had no relevant family history, and the syndrome occurred as a result of a presumed spontaneous mutation.
We feel that these facts are of importance in counselling parents of children with the blepharophimosis syndrome and alerting ophthalmologists to its nonocular manifestations.

\section{References}

1 Dimitry TJ. Hereditary ptosis. Am J Ophthalmol 1921; 4: 655-8.

2 Owens N, Hadley R, Kloepper R. Hereditary blepharophimosis, ptosis epicanthus inversus. J Int Coll Surg 1960; 33: 558-74.

3 Kohn R, Romano PE. Blepharoptosis, blepharophimosis, epicanthus inversus and telecanthus-a syndrome with no name. Am J Ophthalmol 1971; 72: 625-31.

4 Klein M. Hereditary bilateral ptosis and blepharophimosis associated with other developmental abnormalities of the outer eye. Proc R Soc Med 1950; 43: 1025-6.

5 Garden JW. Blepharophimosis, ptosis, epicanthus inversus and lacrimal stenosis. Am J Ophthalmol 1969; 67: 153.

6 McIllroy J. Hereditary ptosis and epicanthus: a case with a pedigree extending over 4 years. Proc $R$ Soc Med 1930; 23: 285-8.

7 Usher C. Epicanthus with ptosis. Trans Ophthalmol Soc UK 1935; 55: 194-232.

8 Usher C. A pedigree of epicanthus and ptosis. Ann Eugenics $1925 ; 1: 126-38$.

9 Waardenburg PJ, Franceschetti A, Klein D. Genetics and ophthalmology. Springfield: Thomas, 1961: 415-43.

10 Townes PL, Muechler EK. Blepharophimosis, ptosis, epicanthus inversus and primary amenorrhea. Arch Ophthalmol 1979; 97: 1664-6. 